\title{
Usability of estimated soil moisture derived from gridded rainfall in agricultural operations
}

\author{
N. CHATTOPADHYAY*, K.MALATHI, N. TIDKE and S.D.ATTRI ${ }^{1}$ \\ Agricultural Meteorology Division, India Meteorological Department, Pune \\ ${ }^{1}$ India Meteorological Department, New Delhi \\ *correspondencenabansu.nc@gmail.com
}

\begin{abstract}
Soil moisture information has not been used extensively under PAN India mode operationally in the country due to sparse network of soil moisture measuring stations. Effort has been made to estimate the soil moisture using gridded rainfall data using soil water balance (SWB) model and subsequently to compare quantitatively with insitu soil moisture measured by gravimetric method. It is observed from the quantitative validation with ground observations that during monsoon season the accuracy with the observed was found to be fairly accurate from the early part of the July to the end of monsoon when the soil was almost recharged with the rainfall. One of the limiting factors is that during dry period and in the low rainfall areas accuracy is relatively low. Thus, the soil moisture information generated using gridded rainfall data can be used from the second month (July) of monsoon season to the end of the monsoon season on PAN India mode for irrigation scheduling and determination of sowing dates and for contingency crop planning etc.
\end{abstract}

Keywords: Soil moisture, soil water balance, gridded rainfall data, geospatial technology, PAN India, operational agromet advisory services

Soil moisture is primary information in achieving optimum water requirements for the crops and very useful for monitoring drought and floods. Soil moisture is generally a highly variable parameter both temporally and spatially, as it is affected by the soil texture, topography, land cover and climate.Soil moisture can be measured using ground observations manually, sensors and satellite remote sensing. Currently in India the operational soil moisture measuring stations are limited. The Thornthwaite Soil Water Balance (SWB) technique is one of the most reliable method for estimating soil moisture (Shweta and Krishna, 2014). The estimates of SWB are used for estimating probable length of growing season, irrigation needs, and fluctuations in water table, drought hazards and soil water availability in different regions and for judging the agricultural potential of the region (Keshav Rao et al. 2008; 2013; Jat et al., 2004; Lalitha et al., 2016). The quantitative results obtained can be utilized for agro meteorological applications and can also be validated with gravimetric soil moisture network.

In present study soil moisture estimation has been made on the bare land and compared with gravimetric soil moisture retrieved from bare soil using gridded rainfall data.

\section{MATERIALS AND METHODS}

\section{Gridded rainfall}

The gridded daily rainfall data generated by IMD over India at a grid resolution of $0.25^{\circ} \mathrm{X} 0.25^{\circ}$ of 2016 for over 3525 rain-gauge stations distributed over India used in the present study were obtained from Climate Prediction Group of IMD which is a joint work of IMD and NCMRWF.

\section{Potential evapotranspiration (PET)}

Weather data for the period (1971-2005) of 144 locations in India for estimation of potential evapotranspiration (PET) by Penman-Monteith equation (Allen et al., 1998) and stored as point data in the GIS software. These point information were interpolated using Shepard's method (simplest form) to prepare spatial raster layers of PET

\section{Soil water balance model (SWB)}

Thornthwaite and Mather (1955) is one of the most widely used due to its simplicity and single layer. This procedure allows estimating the actual evapotranspiration, soil water deficit and excess. The model is simple as it requires knowledge of just three variables, available water capacity(AWC), rainfall (P) and potential evapotranspiration(PET). The soil moisture (SM) is estimated by the formula

$\mathrm{SM}=\mathrm{AWC} * \operatorname{EXP}(\mathrm{APWL} / \mathrm{AWC})$ 
Where SM is soil moisture storage, AWC is available water capacity (difference between the field capacity and wilting point), EXP is exponential and APWL is accumulated negative values of P-PET.

\section{Soil moisture data}

Soil moisture observations were recorded at seven agro meteorological observatories by gravimetric method spread over India Anand (Gujarat), Bangalore (Karnataka), Sabour(Bihar), Jammu (Jammu \& Kashmir), Bhubaneswar and Ranital (Odisha), Kalyani (West Bengal) were used for validation of soil moisture estimated by water balance technique.

\section{RESULTS AND DISCUSSIONS}

The south west monsoon season in India generally begins from $1^{\text {st }}$ of June and covers the entire country by $15^{\text {th }}$ July.Although monsoon affect most parts of India, the amount of rainfall varies from heavy to scanty in different parts. Sowing operations of rain-fed crops in many parts of the country start with receipt of optimum rainfall coinciding with sowing dates of different crops in the country. From Fig. 1 it is observed that in the month of April in 2016 due to the residual soil moisture and some pre-monsoon showers soil was recharged in most parts of the country. However during the middle of May with cessation of pre-monsoon activity soil moisture levels all over the country started receding and eventually there was no agricultural operations being performed under rain-fed condition all over the country. During last week of pre-monsoon month i.e. May, soil moisture stated building up in the North eastern part of the country where usually dry seeding of rice is practiced utilizing this soil moisture. With onset of monsoon in the month of June the southern and eastern part of the country soil started recharging and agricultural operations like seed bed preparation for rice its transplantation etc. along with sowing of many other major crops like cotton, different types of pulse started. By middle of July the soil moisture reserves started increasing in the dry farming tract of the country and other rain-fed regions of the country. Fig. 1 also indicates the general pattern of soil moisture distribution along with intra seasonal variability over the country. Due to intra seasonal variability of rainfall and corresponding soil textures there is an asymmetry in the soil moisture distribution across the country.It is found that increasing soil moisture in the monsoon trough region results in deeper inland penetration and a more developed structure.

\section{Qualitative validation}

Fig. 2 shows the progress of monsoon rainfall in the country from standard week 21(21-27 May) to week 39 (2430 September). Heavy rainfall was observed in North-Eastern states during the standard week 21 and by $27^{\text {th }}$ week it was concentrated in the central India and west coast. The same pattern continued in week no $33^{\text {rd }}$ and shifted toward eastern direction and by $39^{\text {th }}$ week, it concentrated over SubHimalayan West Bengal, Bihar and Telangana. Fig. 3 indicates the progress of available soil moisture over India on weekly basis. It is observed that in week no 21 though both West Madhya Pradesh and Rajasthan falls under same rainfall range but the moisture availability is different (i.e. available water content for the crop), this is due to the variable soil textures in the respective states.During $27^{\text {th }}$ week (2-8 July) the availability of moisture in Rajasthan shows decreasing trend compared to $21^{\text {st }}$ week, but the coastal belt of west India shows increased level of soil moisture for crops. From week no 27 onwards most parts of Madhya Pradesh, North East states and adjoining West Bengal and few places of Odisha and West coast soil is recharged completely and reached field capacity till $33^{\text {rd }}$ week where it completely covered the central part and extended to Telangana and North Coastal Andhra Pradesh. By $39^{\text {th }}$ week as monsoon started retreating and the available water content in these areas started decreasing trend.

\section{Quantitative validation}

Sabour (Bihar) showed a very good accuracy level in field measurements as monsoon progressed in to the state. The model generated soil moisture varied from 86-100 per cent of actual insitu soil moisture measurements (Table 1). Out of 12 observations recorded in Anand (Gujarat), the model generated soil moisture varied from 43-97 per cent of actual insitu soil moisture measurements. However the model was able to capture the variation of soil moisture with respect to rainfall progression in the station.Bangalore (Karnataka) recorded five observations during the season with accuracy of 61-96 per cent of actual value.Jammu (Jammu Kashmir) showed the accuracy of 61-88 per cent of insitu measurements during the season. Bhubaneswar (Odisha) is the only station which showed a good accuracy between 91-100 per cent in pre monsoon season but the performance of model was not up to the mark during the monsoon season. This is due to the fact that district has varied soil textures from loamy to sandy soils in the district. Ranital (Odisha) throughout the season the observed values in station showed good variation with respect to rainfall 

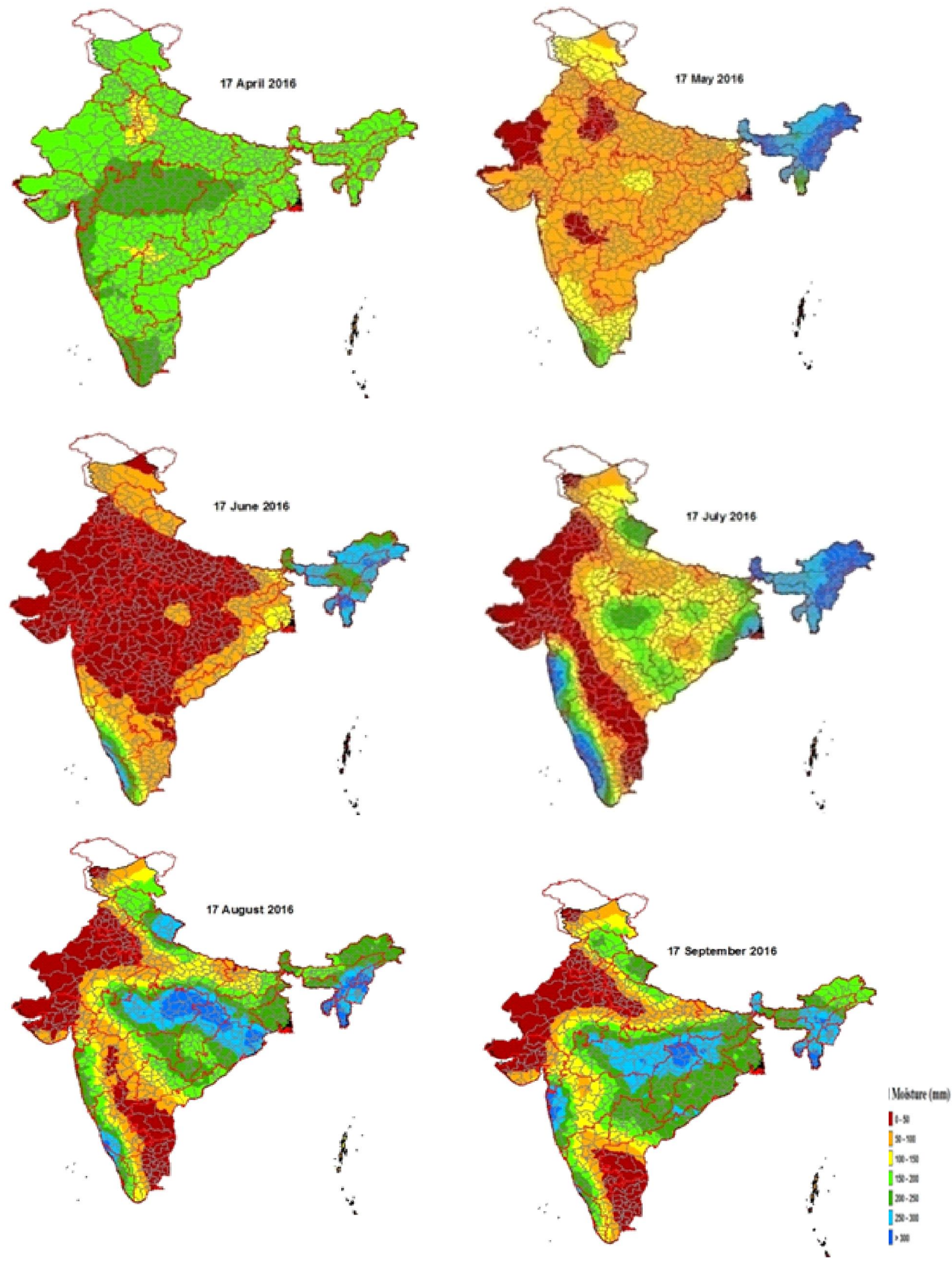

Fig. 1: Availability of soil moisture on daily scale during different monsoon months 

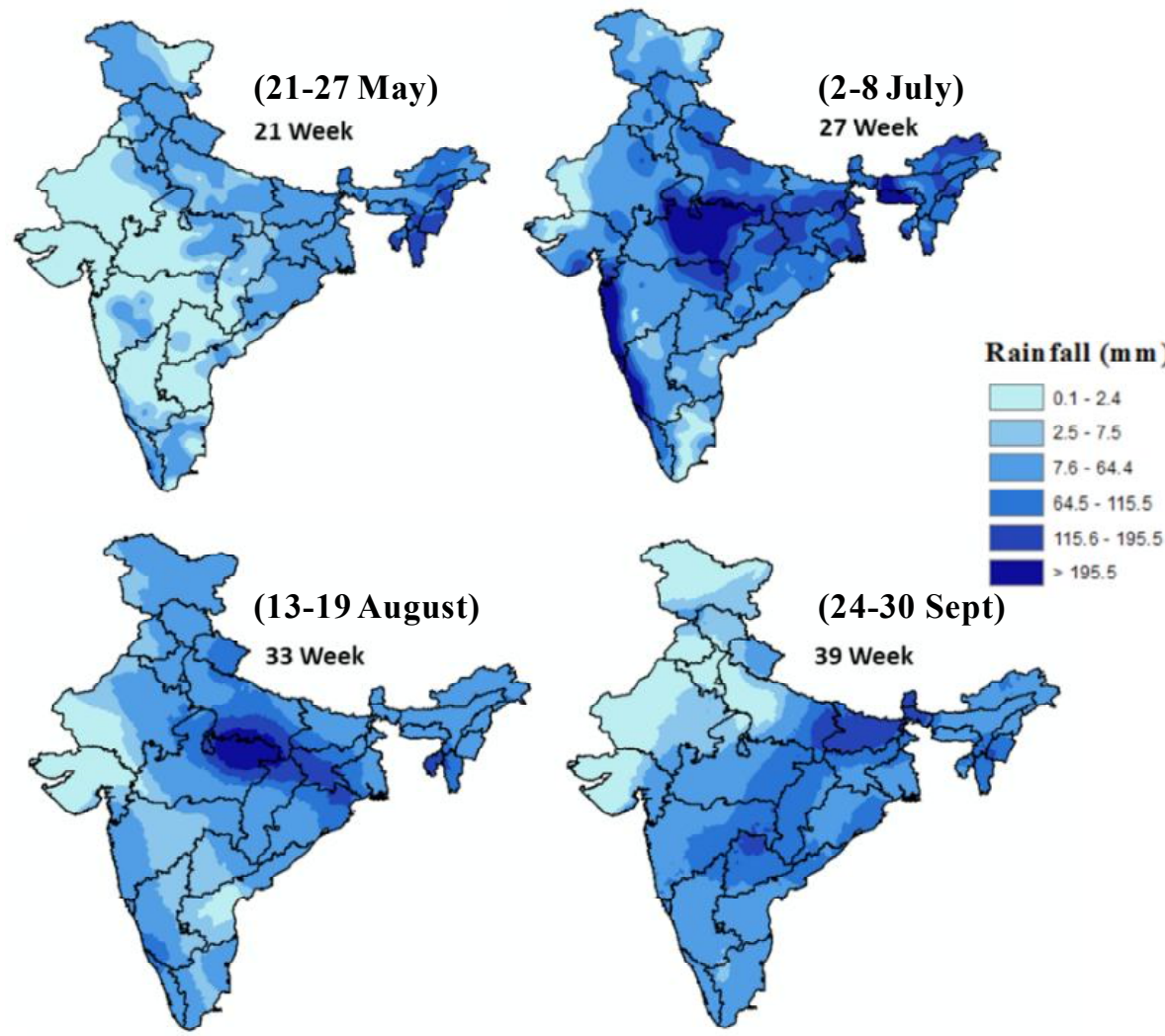

Fig.2: Progress of monsoon rainfall in the country during 2016

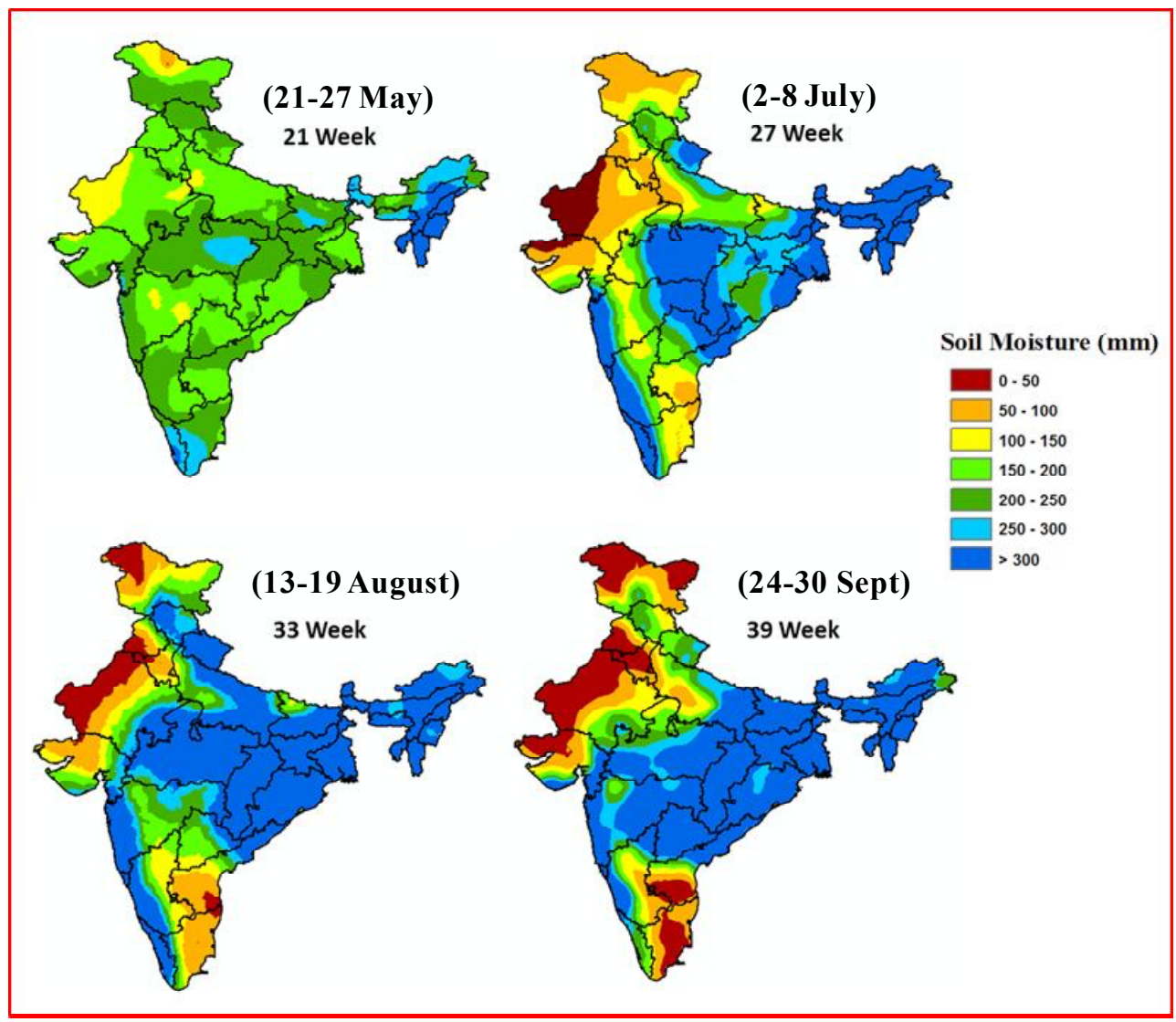

Fig. 3: Progress of available soil moisture during monsoon 2016 
Table 1: Accuracy in \% between insitu soil moisture and soil moisture generated from SWB model

\begin{tabular}{lccccccc}
\hline Std. Week & Anand & Bangalore & Sabour & Jammu & Bhubaneshwar & Ranital & Kalyani \\
\hline 22 & - & - & - & 84 & - & - & 73 \\
23 & - & - & - & 66 & 100 & 68 & 71 \\
24 & - & - & - & 87 & 91 & 68 & 66 \\
25 & - & - & - & 77 & 96 & 48 & 88 \\
26 & - & - & - & 61 & 66 & 57 & 77 \\
27 & 48 & - & 96 & 79 & 3 & 66 & 85 \\
28 & 43 & - & 100 & 89 & 37 & 75 & 76 \\
29 & 53 & - & 95 & 62 & 31 & 88 & 67 \\
30 & 68 & - & 89 & - & 37 & 72 & 60 \\
31 & 56 & - & 89 & - & 79 & 88 & 64 \\
32 & 85 & - & 89 & - & 89 & 92 & 70 \\
33 & 78 & - & 89 & 77 & 38 & 80 & 63 \\
34 & 67 & 83 & 91 & 77 & 34 & 92 & 59 \\
35 & 76 & 74 & 90 & 88 & 39 & 99 & 75 \\
36 & 97 & 96 & 86 & 80 & 24 & 82 & 90 \\
37 & 74 & 61 & 89 & 83 & 19 & 91 & 90 \\
38 & 82 & 76 & 87 & 78 & 48 & 91 & 86 \\
39 & 69 & 64 & 86 & 82 & 19 & 89 & - \\
\hline
\end{tabular}

within the range of 75 to 99 per cent of observed moisture level.Kalyani (West Bengal) showed a consistent acuuracy of 60-90 per cent all through the season (Table 1).

Out of seven stations, five stations (Sabour, Jammu, Ranital, Anand and Kalyani) the accuracy level is relatively high. Another important feature noticed, i.e. during monsoon season the accuracy was found to be good from the early part of the July to the end of monsoon when the soil was almost recharged with the rainfall. Comparatively the high accuracy error in Kalyani compared to the other stations in the beginning of monsoon season may be due to the receipt of rainfall in the pre-monsoon and ultimately contributing increased soil moisture at ground level.

In view of above, soil moisture estimated from gridded rainfall can be used on a regional scale to monitor the soil water budget and to provide agromet advisories for irrigation scheduling and determination of sowing dates, contingency planning, pest and disease warning etc. under operational Agromet Advisory Services on real time.

\section{CONCLUSIONS}

The preliminary study suggests that the gridded rainfall used in the model is more accurate in depicting spatial and temporal variability of rainfall than point
data.Trend of variation of soil moisture estimated using gridded rainfall is almost in accordance with the variation of rainfall and soil texture.However, it is more accurate during July to the end of monsoon of most of the stations. Soil moisture estimated using the SWB technique is available on real time and with little modification and assumption the SM at root zone can be derived and integrated in different hydrological and weather forecast models.

\section{REFERENCES}

Allen, R. G., Peseira, I. S., Daes, D. and Smith, M., (1998). Crop evapotranspiration, Guideline for computing crop water requirements, irrigation and drainage, Paper No.56, FAO, Rome, Italy.

Kesava Rao, A.V.R., Wani,S.P. Singh, Piara, Rao, G.G.S.N., Rathore, L.S. and Sreedevi, T.K. (2008). Agroclimatic assessment of watersheds for crop planning and water harvesting, J. Agrometeorol., 10(1):1- 8.

Kesava Rao,A.V.R.,Wani,S.P. Singh,K.K.,Ahmed, M.I., Srinivas, K.,Bairagi, S.D. and Ramadevi, O. (2013). Increased arid and semi-arid areas in India with associated shifts during 1971-2004. J. Agrometeorol.,15(1):11- 18.

Lalitha, M., Mani, S. and Sivasamy, R.(2016).Crop water 
budgeting for rainfed cotton for crop planning and management in Coimbatore, J. Agrometeorol., 18(2): 265-269)

Jat, M.L., Singh, Raj Vir, Baliyan, J.K. and Kumpawat, B.S. (2004). Water balance studies for agricultural planning in Udaipur region, J. Agrometeorol., 6(2):280-283. computation of AridityIndex and to Assess Water Deficit/ Surplus Months for Seasonal Crop Planning.Inter. $J$. Earth Sci. Engg., 7(3):948-951.

Thornthwaite, C.W. andMather, J.R.,(1955). TheWater Balance. Publ.in Climatology, vol.8, no.1.C.W. Thornthwaite\& Associates, Centerton, New Jersey

Shweta and Krishna A. P., (2014).A Water Balance study for 